\title{
Parents' Satisfaction with Nursing Care for Pediatric Gastrointestinal Endoscopy Patients in Khartoum State Public Hospitals Khartoum, Sudan
}

\author{
Selwa Y Abdeldafie ${ }^{1}$ Bindu Kaipprettu Abraham ${ }^{2}$ \\ ${ }^{1-}$ Assistant Professor of Pediatric Nursing, Nursing Department/College of Applied Medical Sciences/ \\ University of Hafr Albatin KSA \\ ${ }^{2-}$ Msc of Pediatric Nursing, Nursing Department/College of Applied Medical Sciences/ University of Hafr \\ Albatin KSA
}

\begin{abstract}
:
Objective: the aim of this study was to estimate the parents' satisfaction with nursing care provided for their children in endoscopy procedures.

Methods: cross sectional hospital-based design was used and 196 parents were interviewed in Khartoum state public hospitals A consecutive non-probability sampling technique was used. The collected data was cleaned, summarized, analyzed using SPSS version 20.0 and presented in figures and tables.

Results: The caregivers of the children were 196 and they might be the parents or others; 82(41.8\%) of them were females and $114(58.2 \%)$ were males.

Regarding the kind reception by the nurses; 184(93.9\%) of parents or care givers acknowledged the kind reception. 65 (33.2\%) of the caregivers received information about endoscopy procedure from nurses. 126 (64.3\%) caregivers paid the fees for endoscopy procedures from their own resources while the remaining 70 $(35.6 \%)$ were covered by health insurance.

No relation between participants' gender and their satisfaction $P-$ Value $=0.839$ However there is a strong association between participants' satisfaction and their residence with $P$-Value $=0.043$ and participant satisfaction and their monthly income $P$-Value $=0.023$.

Conclusion: the study concluded that although participants were not satisfied about distribution of services mainly in the capital and centre, they were satisfied about nurses' attitude towards their children and acknowledged their kind reception for patients. Only one third of patients were covered by health insurance.

Keywords: Satisfaction, Parents, Children, Endoscopy, Khartoum state
\end{abstract}

\section{Introduction}

Parents' satisfaction is considered as meaning ful information to take an action for quality in health care settings. ${ }^{1}$ Patients, parents or family and guardians' satisfaction with health care is regarded as an important indicator in measuring quality of health care services including nursing care. It is found to be very effective in measuring the success of health institutes and health professionals in delivery of patient care. ${ }^{2}$ Satisfaction of Patients, parents or family and guardians is considered as a desirable outcome of health care which has a lot of dimensions such as environment, waiting times, locations and psychosocial aspect of care received by Patient, parents or family and guardian. ${ }^{(3)}$ Gastrointestinal endoscopy is defined as: the examination which permits direct visualization of the gastrointestinal tract to assess the appearance and integrity of the gastrointestinal mucosa, detect lesions and provide access for therapeutic procedures, it is safe and effective ${ }^{.(4)(5)}$

With the advancement of technology, new innovations in medicine and introduction of fiber optic endoscopy and equipments in pediatric, the pediatric endoscopy procedures has been performed effectively and successfully. In addition to that endoscopic procedures have been performed on children in all stages of growth even premature infants with an increasing rate of using this type of technology. ${ }^{(6)} \mathrm{mSignificant}$ advances have occurred in diagnostic and therapeutic paediatric endoscopy since the first report of its use in children in the 1970s. The last two decades has seen an exponential growth in published experience and innovation in the field of paediatric therapeutic endoscopic intervention in the upper gastrointestinal (GI) tract and is the subject of this review $^{(7)}$ The execution of pediatric gastrointestinal endoscopy has been enhanced during the past two decades by a lot of factors like: dramatic improvements in fiber optic and video technology, conscious sedation, nursing support and physician's experience ${ }^{(8)}$ The success of the gastrointestinal endoscopy and its good out comes is permitted by good understanding of preparing both children and their families by providing sufficient information that help eliminating anxiety, worries and fears due to separation during the procedure.Ageappropriate explanation of the procedure for the children and their parents is helpful reduce fears of the parents and enables the child tolerating the procedure thus parents should be present during the preprocedural educational period to facilitate psychological preparation of both child and parents. ${ }^{(9)(10)(11)(12)(13)}$

DOI: 10.9790/1959-06030196102 www.iosrjournals.org 96|Page


It is necessary to obtain an informed-consent for gastrointestinal endoscopy as well as providing sufficient information about potential risks of the procedure, the benefits of it, and the use of sedation the steps in the procedure. The important elements of this discussion should then be acknowledged in writing. Writing and signing of the informed consent form enforces a sense of trust between the patient and the physician, and provides legal documentation. . ${ }^{10)(11)(12)(13)}$

Objective: The objective of the study was to estimate the parents' satisfaction with nursing care provided for their children in endoscopy procedures, in order to use it as an indicator to measure the quality of nursing care for children undergoing pediatric gastrointestinal endoscopy.

\subsection{Study design:}

\section{Methods}

This study is a descriptive cross sectional hospital-based work which was conducted in Khartoum State public hospitals that provide pediatric gastrointestinal endoscopy services for children.

\subsection{Study settings:}

Khartoum State is one of the 15 States of Sudan covering an area of $22,122 \mathrm{~km}^{2}$ and an estimated population of approximately 7,152,102 (2008 census). Khartoum city is the national capital of Sudan and also the capital of Khartoum State. ${ }^{(48)}$

The study was conducted in public hospitals in Khartoum State that provide pediatric gastrointestinal endoscopy services which are:

Omdurman Teaching Hospital endoscopy unit: which providing diagnostic upper and lower gastrointestinal endoscopy for both children and adults in addition to sclerotherapy for adults.

Omdurman Military Hospital endoscopy unit: which providing diagnostic upper and lower endoscopy for pediatric and adults in addition to sclerotherapy for adults.

East Nile Hospital endoscopy unit: which providing diagnostic and therapeutic upper and lower gastrointestinal endoscopy services except endoscopy capsule and endoscopic retrograde cholangiopancreatography in addition to other types of endoscopy like urodynaminc.

\subsection{Study populations:}

It included all parents and caregivers accompanying their children who underwent pediatric gastrointestinal endoscopy procedures in the target hospitals.

\subsection{Inclusion criteria:}

All parents and caregivers who came with their children for gastrointestinal endoscopy procedures.

A valid consent from the parents and caregivers for participation in the study.

\subsection{Exclusion criteria:-}

Parents who came with their children for other types of endoscopy procedures rather than gastrointestinal endoscopy.

Refusal to participate in the study.

2.6 Sampling technique and Sample size:

Consecutive none probability sampling technique is the suitable type for this study. ${ }^{(14)}$

The sample was drawn from the population by the equation:

$\mathrm{n}=\mathrm{z}^{2} \mathrm{pq} / \mathrm{e}^{2(15)}$

Where: $\mathrm{n}=$ sample size , $\mathrm{z}=1.96, \mathrm{p}=$ prevalence of pediatric gastrointestinal endoscopy $=0.5$

and $\mathrm{q}=1-\mathrm{p}=0.5$

$\mathrm{e}=0.05$

So sample is 384 but a total of 196 consecutive parents and care givers were interviewed and asked about the quality of nursing care received by their children who underwent gastrointestinal endoscopy.

\subsection{Study variables:}

Study variable included background data such as gender, age monthly income, residence and dependent and independent variables like: explanation of the procedure by nurses, kind receiving of patients by nurses, supportive attitude of nurses towards pediatric patients and the satisfaction about the nursing services.

\subsection{Ethical consideration:-}

The study proposal was ethically cleared and endorsed by the Research Department in the State Ministry of Health and the Research Committee in the Faculty of Medicine and Health Sciences, Al Neelain University. It was also officially endorsed by the ethical committee in the Hospitals where the study was conducted.

Any participant (parent, caregiver or older child) was informed about the aims of study and his/her role as a participant, and then a verbal consent was taken. These formalities were done before launching the program of data collection.

The parents and care givers were interviewed face to face to fill in the structured questionnaire providing privacy and confidentiality.

\subsection{Data collection techniques:}


Data were collected by interviewing. The children' caregivers were interviewed in a confidential way to estimate their satisfaction with the quality of nursing care provided for their children in the endoscopy unit.

\subsection{Data collection tools:}

A structured questionnaire developed by the researcher was used to collect information about the caregivers' demographic factors such as gender, age, educational level, monthly income of the family and satisfaction with the quality of pediatric gastrointestinal endoscopy services. These were obtained by total satisfaction which was categorized as high when it ranged between 4 and 6, moderate when it 2-3 and poor it was below 2 .

The six points or marks were the output of the answers of questions about satisfaction including: the waiting time of the procedure, availability of the services, the cost of the services, the attitude of nurses towards children, the quality of the provided services and the preparatory state of the unit to provide the services under the study.

\subsection{Pre-testing of the Questionnaire:-}

The questionnaire, by which information about caregivers' satisfaction obtained, was pre-tested for applicability as a tool for data collection in 10 volunteers (who were excluded from participation in the study) prior to commencement of data collection and it was found to be understandable and applicable.

\subsection{Data processing and analysis:}

Univirate analysis was used for the background variables and bivirate analysis for dependent and independent variables. Data were processed and analyzed by the computer program which is SPSS version 17.0. The caregivers' satisfaction questionnaire was presented in form of frequency tables and cross tabulation to assess the significance. The results were accepted when P.value is less than $0.05(5 \%)$.

\section{Results}

$58.2 \%$ were males and $41.2 \%$ percent were females and about half of them resided in Khartoum state followed by the centre and this revealed the availability of services in the capital.30.6\% of them have low income

Table (1): Distribution of socio-demographic data among parents and care givers $(n=196)$

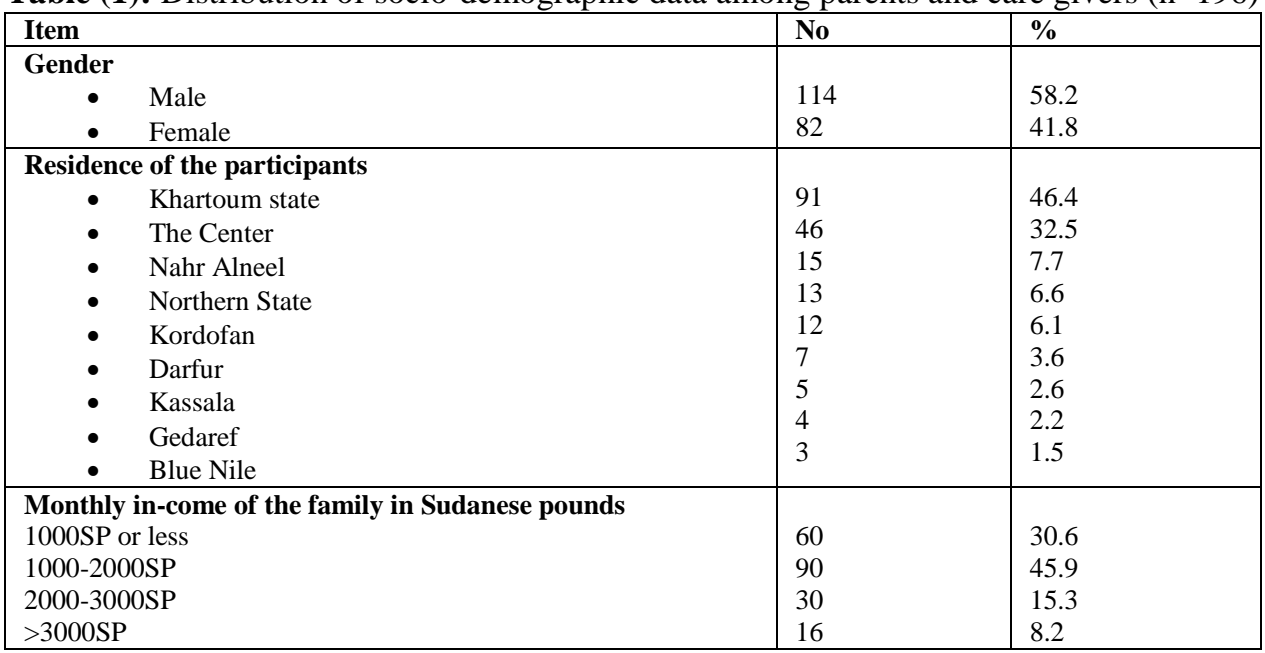

Table 2 showed the vast majority of them were satisfied about the waiting time, preparedness of the unit to provide services and the nurses' attitude towards their children.

Table (2): Distribution of satisfaction among parents and care givers $(n=196)$

\begin{tabular}{|l|l|l|}
\hline Item & No & $\%$ \\
\hline $\begin{array}{l}\text { Satisfaction with the waiting time } \\
\bullet \quad \text { Yes }\end{array}$ & 192 & 98 \\
$\bullet \quad$ No & 4 & 2 \\
\hline $\begin{array}{l}\text { Satisfaction with the preparedness of the unit for services } \\
\text { Yes }\end{array}$ & 190 & 96.9 \\
No & 6 & 3.1 \\
\hline $\begin{array}{l}\text { Satisfaction with nurses' attitude towards their children } \\
\text { Yes }\end{array}$ & 192 & 98 \\
No & 4 & 2 \\
\hline
\end{tabular}

Table 3 showed two third of the parents and caregivers paid the fees from their own resources and only one third is covered by health insurance.

Table (3): fees of endoscopy and affordability to pay it among parents and care givers $(n=196)$ 


\begin{tabular}{|l|l|l|}
\hline Item & No & \% \\
\hline Payment of endoscopy fees & 126 & \\
Yes & 0 & 64.3 \\
No & 70 & 0 \\
Insurance & & 35.7 \\
\hline Suitability of the fees to be paid & 19 & \\
Yes & 177 & 9.7 \\
No & & 90.3 \\
\hline Affordability to pay & 43 & \\
Yes & 153 & 21.9 \\
No & & 78.1 \\
\hline
\end{tabular}

In Figure (1) Three quarters (74.5\%) were totally satisfied with the services provided to their children; about one quarter (21.9\%) of them was moderately satisfied while only (3.6\%) were not satisfied.

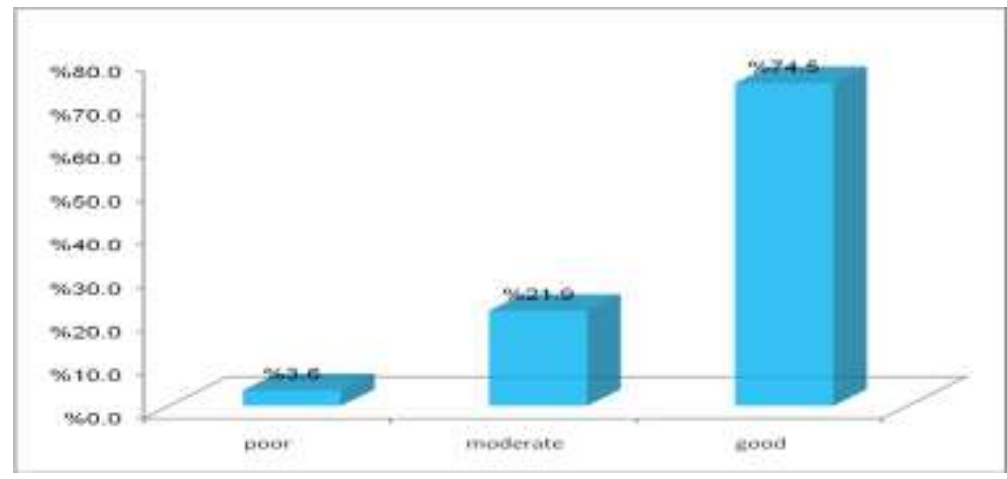

Figure (1): Distribution of the total satisfaction among parents and care givers (n=196)

Table 4: There is no relationship between the gender of parents and care givers and the satisfaction with the provided services $(\mathrm{p}$ - value $=0.570)$

Table (4): Parents' Satisfaction by their gender $(\mathrm{n}=196)$

\begin{tabular}{|l|l|l|l|}
\hline Parents' satisfaction with the provided services by gender & Male & Female & Total \\
\hline Good & 28 & 64 & 146 \\
& $71.9 \%$ & $78.0 \%$ & $74.5 \%$ \\
\hline Moderate & $56.2 \%$ & $43 . \%$ & $100.0 \%$ \\
\hline Poor & 27 & 16 & 43 \\
& $23.7 \%$ & $19.5 \%$ & $21.9 \%$ \\
& $62.8 \%$ & $37.2 \%$ & $100.0 \%$ \\
\hline Total & 5 & 2 & 7 \\
& $4.4 \%$ & $2.4 \%$ & $3.6 \%$ \\
& $71.4 \%$ & $28.6 \%$ & 100.0 \\
\hline
\end{tabular}

P-value $=0.570$

In table 5: parents and care givers' satisfaction had a significant relationship with the residence because accessibility is important in providing the services and in this study about half of the study units came from Khartoum followed by the center $(p$ - value $=0.043$

Table(5): Parents 'Satisfaction according to their Residence ( $\mathrm{n}=196)$

\begin{tabular}{|l|l|l|l|l|}
\hline \multirow{2}{*}{ Residence of the parents or care givers } & \multicolumn{2}{l|}{ Satisfaction } & Total \\
\cline { 2 - 5 } & poor & moderate & good & \\
\hline Khartoum & 2 & 10 & 36 & 48 \\
\hline & $4.2 \%$ & $20.8 \%$ & $75.0 \%$ & $100.0 \%$ \\
\hline Khartoum North & $28.6 \%$ & $23.3 \%$ & $24.7 \%$ & $24.5 \%$ \\
\hline & 0 & 3 & 17 & 20 \\
\hline & $.0 \%$ & $15.0 \%$ & $85.0 \%$ & $100.0 \%$ \\
\hline Omdurman & $.0 \%$ & $7.0 \%$ & $11.6 \%$ & $10.2 \%$ \\
\hline & 0 & 8 & 15 & 23 \\
\hline & $.0 \%$ & $34.8 \%$ & $65.2 \%$ & $100.0 \%$ \\
\hline Center & $.0 \%$ & $18.6 \%$ & $10.3 \%$ & $11.7 \%$ \\
\hline & 1 & 5 & 40 & 46 \\
\hline
\end{tabular}


Parents' Satisfaction with Nursing Care for Pediatric Gastrointestinal Endoscopy Patients in

\begin{tabular}{|l|l|l|l|l|}
\hline & $14.3 \%$ & $11.6 \%$ & $27.4 \%$ & $23.5 \%$ \\
\hline Kordofan & 2 & 5 & 5 & 12 \\
\hline & $16.7 \%$ & $41.7 \%$ & $41.7 \%$ & $100.0 \%$ \\
\hline Darfur & $28.6 \%$ & $11.6 \%$ & $3.4 \%$ & $6.1 \%$ \\
\hline & 1 & 0 & 6 & 7 \\
\hline & $14.3 \%$ & $.0 \%$ & $85.7 \%$ & $100.0 \%$ \\
\hline Blue Nile & $14.3 \%$ & $.0 \%$ & $4.1 \%$ & $3.6 \%$ \\
\hline & 0 & 2 & 1 & 3 \\
\hline & $.0 \%$ & $66.7 \%$ & $33.3 \%$ & $100.0 \%$ \\
\hline Nahar alnile & $.0 \%$ & $4.7 \%$ & $.7 \%$ & $1.5 \%$ \\
\hline & 1 & 4 & 10 & 15 \\
\hline & $6.7 \%$ & $26.7 \%$ & $66.7 \%$ & $100.0 \%$ \\
\hline Kassala & $14.3 \%$ & $9.3 \%$ & $6.8 \%$ & $7.7 \%$ \\
\hline & 0 & 3 & 2 & 5 \\
\hline & $.0 \%$ & $60.0 \%$ & $40.0 \%$ & $100.0 \%$ \\
\hline Gedaref & $.0 \%$ & $7.0 \%$ & $1.4 \%$ & $2.6 \%$ \\
\hline & 0 & 0 & 4 & 4 \\
\hline & $.0 \%$ & $.0 \%$ & $100.0 \%$ & $100.0 \%$ \\
\hline North & $.0 \%$ & $.0 \%$ & $2.7 \%$ & $2.0 \%$ \\
\hline & 0 & 3 & 10 & 13 \\
\hline
\end{tabular}

$\mathrm{p}-$ value $=0.043$

Table 6 revealed that there is significant relation between the monthly income of the family and the satisfaction of parents and care givers ( $p$-value $=0.023$ ) this was expressed by parents affordability to pay the fees of endoscopy and their satisfaction about that fees,

Table (6): Parents' Satisfaction by monthly family income $(\mathrm{n}=196)$

\begin{tabular}{|l|l|l|l|l|l|}
\hline $\begin{array}{l}\text { Monthly income of } \\
\text { the family }\end{array}$ & Less than750sdg & $\mathbf{7 5 0 - 1 5 0 0 s d g}$ & $\mathbf{1 5 0 0 - 2 2 5 0 s d g}$ & $\begin{array}{l}\text { More than } \\
\mathbf{2 2 5 0 s d g}\end{array}$ & Total \\
\cline { 1 - 5 } Satisfaction & & & & \\
\hline Poor & $7(6.4 \%)$ & $0(0.0 \%)$ & $0(0.0 \%)$ & $0(0.0 \%)$ & $7(3.6 \%)$ \\
& $100.0 \%$ & $0.0 \%$ & $0.0 \%$ & $0.0 \%$ & $100.0 \%$ \\
\hline Moderate & $28(25.5 \%)$ & $7(10.9 \%)$ & $3(42.9 \%)$ & $5(33.3 \%)$ & $43(21.9 \%)$ \\
& $65.1 \%$ & $16.3 \%$ & $7.0 \%$ & $11.6 \%$ & $100.0 \%$ \\
\hline Good & $75(68.2 \%)$ & $57(89.1 \%)$ & $4(57.1 \%)$ & $10(66.7 \%)$ & $146(74.5 \%)$ \\
& $51.4 \%$ & $39.0 \%$ & $2.7 \%$ & $6.8 \%$ & $100.0 \%$ \\
\hline Total & $110(100.0 \%)$ & $64(100.0 \%)$ & $7(100.0 \%)$ & $15(100.0 \%)$ & $196(100.0 \%)$ \\
& $56.1 \%$ & $32.7 \%$ & $3.6 \%$ & $7.7 \%$ & $100.0 \%$ \\
\hline
\end{tabular}

p-value $=0.023$

\section{Discussion.}

Pediatric patients cannot express their opinions in term of satisfaction or dissatisfaction so parents might take the responsibility to express their satisfaction with the provided services. ${ }^{(2)}$. Now days satisfaction of family and patients is regarded as indicator for measuring quality in health care setting (16)

Gastrointestinal (GI) endoscopy is regarded as a useful diagnostic and therapeutic tool for different pediatric gastrointestinal diseases ${ }^{17)}$. To prepare children for gastrointestinal endoscopy, health care providers such as nurses should pay attention to psychological and emotional issues , therefore providing explanation can enhance child tolerance for the procedure and relieve parents anxiety (9) (10) (11) (12) (13) (17) (18)this study $33.2 \%$ of the studied sample received explanation of the procedure by nurses in charge .This results agreed with(16) Latour et al. who reported that giving explanation and information and understanding of psychoemotional needs by nurses and perceiving their effects on satisfaction of parents will positively affect parents satisfaction also (17) agreed on this (19). ${ }^{(2)}$ Naiire Salmani and colleagues(2015) stated that parents and family need to be reassured about their children problems $\left((20)\right.$ but Khour $\mathrm{H}^{1}$, Perreault $\mathrm{P}(2010)$ found that information which given for patients and caregivers about preprocedural medications was insufficient .

The present study revealed that vast majority of parents were satisfied with the waiting time for the procedures, according to (21) the length of time spent by patients and families is very important to determine their satisfaction with the services. $n$ emergency department (ED) patient satisfaction surveys, waiting time is one of the most frequently mentioned concerns of patients and parents. In almost all studies it ranks above any concerns with actual treatment received or problems with staff communication ( 1 ). The waiting time is especially of concern for those patients who have less urgent or nonurgent problems and it is evident that the 
expectation of the public is that all care in an ED should be provided rapidly. At the same time, studies have shown that the perception of waiting times by parents and patients are often longer than the reality (22) In this study, parents and care givers were totally satisfied about the hospitals providing the services this means that: more prepared hospital with available services gains the more satisfaction of parents and care givers.(see table ) Parents and care givers 'gender does not influence their satisfaction while their monthly income affects it, this was expressed by parents affordability to pay the fees of endoscopy and their satisfaction about that fees. (see table ) The same influence happened with residence because accessibility is important in providing the services and in this study about half of the study units came from Khartoum followed by the center. (See table)

\section{Limitations}

The study did not cover endoscopic retrograde cholangiopancreatography and endoscopy capsule because target hospitals did not provide these services.

\section{Conclusion}

Parents and care givers were satisfied about nurses' attitude towards their children, the availability of services, but they were not satisfied about the cost of the procedures and there is only one third of the studied sample under the umbrella of the health insurance.

\section{Recommendation}

Pediatric gastrointestinal endoscopy services should be available in all states so as to achieve the accessibility of service and satisfaction of patients and parents.

-Nurses and endoscopy technicians should be educated about the patients and parents satisfaction as an indicator to measure the quality of care.

Health insurance services should be expanded to cover more pediatric population.

Researches should be conducted to map the experience in this field.-

\section{References}

[1]. Rashid A and Amina A :( 2014) Patient Satisfaction Survey as a Tool Towards Quality Improvement Oman Med: Oman Med J. 2014 Jan; 29(1): 3-7. doi: 10.5001/omj.2014.02At: https://www.ncbi.nlm.nih.gov/pmc/articles/PMC3910415/

[2]. Naiire S, Abbas A, Maryam R and Shirin H:(2015) The Process of Satisfaction with Nursing Care in Parents of Hospitalized Children: A Grounded Theory Study International ajaournal of pediatric Volume 3, Issue 6.1, November 2015, Page $1021-103$

[3]. Shin-ichiro H etal (2015), Pediatric Patient and Parental Anxiety and Impressions Related to Initial Gastrointestinal Endoscopy: A Japanese Multicenter Questionnaire Study Volume 2015 (2015), Article ID 797564, 7 pages available at: http://dx.doi.org/10.1155/2015/797564

[4]. Amy Carpenter Aquino ,MS: SGNA Gastroenterology Nursing $4^{\text {th }}$ edition 2008 congress cataloging USA

[5]. Akash N, Muhammed S, Charles S and Subbaramia S:( )Diagnostic Endoscopy Georgia Health Sciences University, U. S. A available at $:$ http://cdn.intechopen.com/pdfs/43598/intech-diagnostic_endoscopy.pdf

[6]. RobertH,Squires JR: Medical Position Paper: Indications for Pediatric Gastrointestinal Endoscopy: A Medical Position Statement of the North American Society for Pediatric Gastroenterology and Nutrition Volume 23 - Issue 2 - pp 107-110 at: http://naspgn.org/endoscopy.htm

[7]. Imdadur Ra, Praful P and Philip B:(2015) Therapeutic upper gastrointestinal tract endoscopy in Paediatric Gastroenterology World J Gastrointest Endosc. 2015 Mar 16;7(3):169-82. doi: 10.4253/wjge.v7.i3.169.

[8]. Sabir,OM and Gadour, MO:( 2007)Upper Gastrointestinal Endoscopy in Sudanese Infants and Children Sudan Medical Journal Vol.2 No2 P: 91-94 Available at: http://www.smjms.net/issues/2-2/html/4-uppergastrontestinal

[9]. Korean journal of pediatrics :general considerations and updates in pediatric gastrointestinal diagnostic endoscopy at http://www.ncbi.nlm.nih.gov/pmc/articles /PMC3005212

[10]. practical endoscopy page 297 Mike Shephard and JayneMason - chapman and hallmedical UK 1997 first edition-chapman and Hall Medical -London) Shephard M and Mason J: practical endoscopy (1997) first edition chaman and Hallmedical UK London.

[11]. Pediatric gastrointestinal endoscopy text book and atlasHarland S. Winter 2006BC Decker Hamilton Ontario

[12]. NASPGHANguideline:Modifications in endoscopic practice for pediatric patients volume 67,no.1:2008 at www.giejournal.org gastrointestinal endoscopy procedure at http://www.healthplus24.com/disease/digestive-health/gastrointest..

[13]. Joseph JC: non-probability sampling 2009 at: http://www.Explorable.com/non-probability-sampling

[14]. Sample Size Formulas for our Sample Size Calculator at: www.surveysystem.com/sample-size-formula.htm

[15]. Jos M Latour etal :(2013) The shortened EMpowerment of PArents in THe Intensive Care 30 questionnaire adequately measured parent Journal of Clinical Epidemiology 66 (2013) 1045e

[16]. Abdulkerim T:(2015) Efficiency of upper gastrointestinal endoscopy in pediatric surgical practice

[17]. World J Clin Pediatr. 2015 Nov 8; 4(4): 113-119. Published online 2015 Nov 8. doi: 10.5409/wjcp.v4.i4.113 available at: https://www.ncbi.nlm.nih.gov/pmc/articles/PMC4637801/

[18]. American Society For Gastrointestinal Endoscopy:Modifications in Endoscopic Practice for Pediatric Patients GASTROINTESTINAL ENDOSCOPY VOLUME 52, NO. 6, 2000 838-842

[19]. Eman S A, Youssria E Y . Nagla H A F and Naglaa A M:(2016) Effect of Preparation Program on Anxiety Level of Children Undergoing Endoscopy IOSR Journal of Nursing a nd Health Science (IOSR-JNHS) e-ISSN: 2320-1959.p- ISSN: 2320-1940 Volume 5, Issue 4 Ver. II (Jul. - Aug. 2016), PP 43-49 available at: www.iosrjournals.org

[20]. Fitzpatrick N, Breen DT, Taylor J, Paul E, Grosvenor R, Heggie K, Mahar PD:(2014) Parental satisfaction with paediatric care, triage and waiting times Emerg Med Australas. 2014 Apr;26(2):177-82. doi: 10.1111/1742-6723.12202.

[21]. Bhanu P:(2010) Patient Satisfaction J Cutan Aesthet Surg v.3(3); Sep-Dec 2010 PMC3047732 
[22]. Smaranda D etal:(2015) pre-procedural recommendations in Pediatric gastrointestinal endoscopy , ROMANIAN JOURNAL OF PEDIATRICS - VOL. LXIV, NO. 4, YEAR 2015

[23]. David M G :(2003) When should waiting time become a quality of care issue in the paediatric emergency department? Paediatr Child Health. 2003 Sep; 8(7): 415-416. available at: https://www.ncbi.nlm.nih.gov/pmc/articles/PMC2791648/ 